\title{
Comprehensive HIVIAIDS knowledge level among out-of-school youths in Wayu Tuka district, Western Ethiopia
}

\author{
Gemechu Kejela ${ }^{1, ~ *, ~ L e m e s s a ~ O l j i r a ~}{ }^{2}$, Yadeta Dessie ${ }^{2}$, Direslgne Misker ${ }^{1}$ \\ ${ }^{1}$ Department of Public Health, Arbaminch University, Arbaminch, Ethiopia \\ ${ }^{2}$ Department of Public Health, Haramaya University, Harar, Ethiopia
}

\section{Email address:}

gemechukejela86@gmail.com (G. Kejela),olemessa@yahoo.com (L. Oljira),yad_de2005@yahoo.com (Y. Dessie), diresmisker@gmail.com (D. Misker)

\section{To cite this article:}

Gemechu Kejela, Lemessa Oljira, Yadeta Dessie, Direslgne Misker. Comprehensive HIV/AIDS Knowledge Level among Out-of-School Youths in Wayu Tuka District, Western Ethiopia. European Journal of Preventive Medicine. Vol. 3, No. 1, 2015, pp. 11-16. doi: $10.11648 /$ j.ejpm.20150301.13

\begin{abstract}
Background: Although there is a high awareness about HIV/AIDS prevention methods among youth, in Ethiopia, the problems are still rampant which indicates lack of comprehensive knowledge about its prevention methods among young peoples. Objectives: the main aim of this study was to assess comprehensive HIV/AIDS knowledge level and associated factors among out- of- school youths in Wayu Tuka district. Methods: A community based cross-sectional study was conducted. The data was collected using structured questionnaire from a total of 709 respondents selected systematically from 6 randomly selected kebeles of the district. Data was entered into EPI data version 3.02 and analyzed by using SPSS version 16.0. Multivariable logistic regression was applied to assess the association of the outcome variable and the explanatory variables. Variables with $\mathrm{p}$-value of $<0.05$ at multivariable logistic regression were considered as statistically significant predictors of comprehensive HIV/AIDS knowledge. Result: comprehensive HIV/AIDS knowledge in this study was $25 \%$. Comprehensive HIV/AIDS knowledge was higher among those with secondary (AOR[95\%CI]= 3.38[1.534,7.455] and above $(\mathrm{AOR}[95 \% \mathrm{CI}]=3.47[1.342,8.967]$ educational levels, who live with friends/partners (AOR[95\%CI] $=1.58[1.046,2.399]$ or relatives/other person $\mathrm{AOR}[95 \% \mathrm{CI}]=2.35[1.071,5.171]$, who use media as their major information source $(\mathrm{AOR}[95 \% \mathrm{CI}]=2.17[1.027,4.562])$ and who discussed about sexual matter with their parents (AOR[95\%CI]= 2.36[1.531,3.643]). Conclusions: In this study, comprehensive HIV/AIDS knowledge was low. So, appropriate information education and communication programs needs to be intensified for out-of-school youths in the study area.
\end{abstract}

Keywords: Out-of-School Youths, HIV/AIDS, Comprehensive Knowledge, Wayu Tuka

\section{Background}

Youth is the period of transition from early adolescent to adulthood that comprises individuals between the ages of 15 to 24 . It is a developmental period characterized by marked physical, emotional, behavioral and intellectual changes (1). It is assumed that adolescents/youths are free from ill-health and are considered as the healthiest period of person's life. However, transition through adolescence and youth period is linked with a number of issues that affect their body, behavior, and social interactions (2).

Behaviors that are acquired during adolescence have a great implication for the health of youths and later adult hood.
A great number of young women and men initiate sexual activity during adolescence, and risk for sexually transmitted infections accompanies sexual initiation (3). Globally, majority of HIV infection occur through sexual intercourse between men and women. In sub-Saharan Africa, young people aged $15-24$ represent $40 \%$ of new infections, and many young people still lack access to information, skills and services required to prevent HIV infection (4).

Knowledge about STIs and HIV/AIDS is a prerequisite for the prevention and control of the problem. It is obvious that HIV prevalence depends on knowledge of preventive actions, 
the attitude towards the disease and people's sexual behaviors $(6,1)$. Awareness alone is not enough for the prevention and control of HIV/AIDS and unwanted pregnancy. In Ethiopia, awareness of AIDS is almost universal. However, comprehensive knowledge of HIV/AIDS among youths is uncommon with only $23 \%$ of females and $34 \%$ of males having comprehensive knowledge of HIV/AIDS (5).

To avert RH problems of young peoples, WHO created a program of action to increase youth's reproductive health awareness and knowledge (1). In addition, Ethiopia developed strategies to increase youth's awareness and knowledge about RH issues (7). Despite all these efforts, youth, in general and out-of-school and rural youths in particular often lack access to RH information and services (8). In addition, In Ethiopia, few studies are conducted among youths on this issue and most of the studies conducted in the country so far are based on in school and urban youths. As a result, there is a shortage of information on vulnerable groups like out of school and rural youths. So, the main aim of this study was to assess comprehensive HIV/AIDS knowledge level and associated factors among out of school youths in communities of Wayu tuka district.

\section{Methods}

\subsection{Study Design and Setup}

A community based cross sectional study was conducted in Wayu Tuka district, East Wollega zone of Oromia regional state, western Ethiopia, from January 13-27, 2014. Wayu Tuka district is one of the 18 districts of East Wollega zone, which is located in the Northern part of the zone at $319 \mathrm{~km}$ away from Addis Ababa. Wayu tuka district is sub-divided in to 10 kebeles for its administrative purposes. According to the 2007 Ethiopian census report, the population of Wayu Tuka district was projected to be 66,194 , out of which, 32,116 were females and 34,078 were males. Youths (1524years) account for 9,761 (15\%) of the total population of the district. Of which 3,938 were females and 5,823 were males (9). Source population of this study was all out of school youths residing in Wayu Tuka district and the Study Population were all youths from six randomly selected kebeles found in the district. Out- of- school youths who were not currently attending school were included in the study.

\subsection{Sample Size and Sampling Procedures}

Sample size was calculated using single population proportion formula by taking an assumption of proportion of comprehensive HIV/AIDS knowledge among female youths of $24 \%$ (5), 95\% confidence level, $4 \%$ margin of error, design effect of 1.5 and an addition of $10 \%$ non-response rate The final sample size was computed to be 723 out-of-school youths.

Multistage sampling technique was applied. Procedurally, first by assuming there is a difference in knowledge level between urban and rural youths, all the 10 kebeles in the district were stratified based on their geographical areas as one urban and nine rural kebeles. The urban kebele was taken for comparison purpose and by assuming that rural kebeles are relatively homogenous, five kebeles out of the nine rural kebeles were selected using lottery method. Totally six kebeles were included in the study. Pre-survey was conducted in each selected kebeles to identify households with out of school youths. Thirdly, out of each selected kebeles, households with out of school youths were allocated using PPS. Finally, households with study samples were selected using systematic sampling method. The first house included in the study was selected by lottery method. If there were more than one out of school youths in the same household, one was selected using lottery method. Where there was no respondent (the house was closed), repeated visit up to three times was conducted. In case it was closed after repeated visits, they were documented as nonrespondents.

\subsection{Data Collection Tools}

Structured interviewer administered questionnaire was adopted from EDHS and study conducted on the same topic in different areas and modified based on the study variables and local context. Twelve tenth grade completed data collectors of both sex and two Bsc nurse supervisors were recruited and trained. After training, pre-test was done on 5\% of the sample. Then, data was collected by sex matched data collectors to minimize non-response and social desirability bias. To ensure the quality of data, the questionnaire and consent documents were first developed in English, then translated into local language (Afan Oromo), and finally retranslated into English to check its consistency. Training was given for data collectors and supervisors and the questionnaire was pretested on $36(5 \%)$ of samples who live in kebeles which were not selected for the study before the actual data collection. Supervisors and principal investigator were closely monitored the day-to-day data collection process. Finally data were sorted, checked, entered into the computer and cleaned for analysis.

\subsection{Measurements}

The following operational definitions were used: Out of school Youths were defined in this study as youths who are not currently attending school. Comprehensive HIV/AIDS knowledge was defined as the ability to identify correctly at least two major ways of preventing sexual transmission of HIV (faithfulness to one uninfected partner and condom use), to reject at least two most common local misconceptions about HIV transmission and knowing that a healthy-looking person can have HIV/AIDS virus. Local misconceptions was defined as locally known misunderstanding about the transmission of HIV like transmission by mosquito bites, supernatural means (curse), contact with saliva or sweat of HIV infected person and sharing food with HIV infected person. 


\subsection{Data Processing and Analysis}

Data was entered into Epi data version 3.02 and exported to SPSS version 16.0 for analysis. Frequencies of different variables were determined and followed by cross tabulations to compare their frequencies. Binary logistic regression was conducted for dependent and independent variables and crude odds ratio (COR) with $95 \%$ confidence interval was estimated to assess the association between dependent and in dependent variables. Then variables with $p$-value of $\leq 0.3$ at binary logistic regression were taken into multivariable logistic regression analysis to assess their association with comprehensive HIV/AIDS knowledge. Hosmer-lemeshow goodness-of-fit with stepwise (backward elimination) was used to test for model fitness. Adjusted odds ratio (AOR) with $95 \%$ confidence interval was estimated to assess the presence of association at multivariable logistic regression. Variables with $p$-value of $<0.05$ at multivariable logistic regression were considered as statistically significant predictors of comprehensive HIV/AIDS knowledge. Finally, the analyzed data were summarized using text and tables.

\subsection{Ethical Considerations}

Ethical clearance was obtained from Institutional Health Research Ethics Review Committee of Haramaya University College of Health and medical Sciences. An official letter was written from School of Graduate Studies to Wayu Tuka district administration office. Further written consent was secured from district health office. Also Kebele administrators were communicated through formal letters from district administration office. Signed assent/consent was obtained from parent/guardian and the respondent, for youths between 15-18 age groups and from the respondent only, if he/she was above 18 years, through addressing the necessary explanation about the purpose of the study and its procedure, assurance of confidentiality, privacy and the right to with draw the participation at any time without any consequences. Participants were also assured that, they did not face any problem for their participation in the study.

\section{Results}

\subsection{Socio-Demographic Characteristics of the Respondents}

A total of 723 respondents were included in the study. Of these, 709 of them were responded which resulted in response rate of $98.06 \%$. Males and females constitutes, 439 $(61.9 \%)$ and $270(38.1 \%)$ respectively. The ages of the respondents range from 15 to 24 with mean of 20.06 and standard deviation of 2.458. Majority (95.8\%) of respondent's father and almost all, 598 (99.2\%) of the respondent's mother were farmers and house wife respectively (Table 1).

Majority of the respondents, $(54.2 \%)$ cited media as their major HIV/AIDS information source followed by friends in $25 \%$, health professionals in $12.6 \%$ and family members in $7.8 \%$. Majority of the respondents $394(55.6 \%)$ know both abstinence and faithfulness followed by faithfulness and using condom 311(43.9\%) and abstinence and using condom $298(42 \%)$. Two hundred sixty nine $(37.9 \%)$ of respondents know all the three common prevention methods of sexual transmission of HIV virus. In this study, only $25 \%$ of respondents had comprehensive HIV/AIDS knowledge. Twenty seven percent $(27.3 \%)$ of males and $21.1 \%$ of females had comprehensive HIV/AIDS knowledge (Table 2).

Table 1. Socio-demographic characteristics among out-of-school youths, Wayu Tuka district, western Ethiopia, 2014. (n=709)

\begin{tabular}{|c|c|c|}
\hline Variables & Number & Percent (\%) \\
\hline \multicolumn{3}{|l|}{ Sex } \\
\hline Male & 439 & 61.9 \\
\hline Female & 270 & 38.1 \\
\hline \multicolumn{3}{|l|}{ Age } \\
\hline $15-19$ & 276 & 38.9 \\
\hline $20-24$ & 433 & 61.1 \\
\hline \multicolumn{3}{|l|}{ Residence } \\
\hline Urban & 94 & 13.3 \\
\hline Rural & 615 & 86.7 \\
\hline \multicolumn{3}{|l|}{ Ethnicity } \\
\hline Oromo & 690 & 97.3 \\
\hline Others & 19 & 2.7 \\
\hline \multicolumn{3}{|l|}{ Marital status } \\
\hline Unmarried & 552 & 77.9 \\
\hline Married & 157 & 22.1 \\
\hline \multicolumn{3}{|l|}{ Literacy level } \\
\hline No formal education & 79 & 11.1 \\
\hline Primary & 329 & 46.4 \\
\hline Secondary & 249 & 35.1 \\
\hline 12 and above & 52 & 7.4 \\
\hline Mother alive & 144 & 20.3 \\
\hline \multicolumn{3}{|l|}{ Living arrangement } \\
\hline With parents & 482 & 68 \\
\hline With friends/partners & 190 & 26.8 \\
\hline With relatives/others & 37 & 5.2 \\
\hline \multicolumn{3}{|l|}{ Father's literacy level } \\
\hline No formal education & 387 & 73.2 \\
\hline Primary & 94 & 17.8 \\
\hline Secondary and above & 48 & 9.0 \\
\hline \multicolumn{3}{|l|}{ Mother's literacy level } \\
\hline No formal education & 504 & 83.6 \\
\hline Primary & 84 & 13.9 \\
\hline Secondary and above & 15 & 2.5 \\
\hline
\end{tabular}

Table 2. Comprehensive HIV/AIDS knowledge level among out-of-school youths, Wayu Tuka district,Western Ethiopia, 2014. (n=709)

\begin{tabular}{lll}
\hline Variable & Number & $\begin{array}{l}\text { Percent } \\
(\%)\end{array}$ \\
\hline Comprehensive HIV Transmission knowledge & & \\
Yes & 576 & 81.2 \\
No & 133 & 18.8 \\
Comprehensive knowledge of HIV/AIDS & & \\
diagnosis methods & 463 & 65.3 \\
Yes & 246 & 34.7 \\
No & & \\
Comprehensive HIV/AIDS Prevention & 311 & 43.9 \\
knowledge & 398 & 56.1 \\
Yes & & \\
No & 177 & 25.0 \\
Comprehensive HIV/AIDS knowledge level & 532 & 75.0 \\
Yes & & \\
No & & \\
\hline
\end{tabular}




\subsection{Factors Associated with Comprehensive HIV/AIDS Knowledge}

Multivariable logistic regression analysis shows that respondents with secondary (Adjusted OR $[95 \% \mathrm{CI}]=$ $3.38[1.53,7.46])$ and 12 and above (Adjusted OR [95\%CI] $=3.47[1.34,8.97]$ educational level were more likely to have comprehensive HIV/AIDS knowledge compared to respondents with no formal education. Respondents who live with their friends/partners (Adjusted OR $[95 \% \mathrm{CI}]=$ $1.58[1.046,2.399])$ or relatives/other persons like neighbor (Adjusted OR [95\% CI] $=2.35[1.07,5.17]$ ) were more likely to have comprehensive HIV/AIDS knowledge compared to respondents who live with their parents.

Respondents who cited media as their major HIV/AIDS information source were 2.17 times more likely to have comprehensive HIV/AIDS knowledge compared to those who cited their parents (Adjusted OR[95\%CI]= $2.17[1.03,4.56])$. Respondents who had knowledge of sexually transmitted infections other than HIV/AIDS were 1.95 times more likely to have comprehensive HIV/AIDS knowledge compared to their counterparts (Adjusted OR $[95 \% \mathrm{CI}]=1.95[1.06,3.59])$.

Respondents who had discussed about sexual matter with their parents or other family members were 2.36 times more likely to have comprehensive HIV/AIDS knowledge compared to their counterparts (Adjusted OR [95\% CI] = $2.36[1.53,3.64])$. In this study, variables like sex and having current sexual partner were not associated with comprehensive HIV/AIDS knowledge (Table 3).

Table3. Multivariable logistic regression indicating factors associated with comprehensive HIV/AIDS knowledge among out-of-school youth, Wayu Tuka district, western Ethiopia, 2014.

\begin{tabular}{|c|c|c|c|c|c|}
\hline \multirow{2}{*}{ Variables } & \multicolumn{5}{|c|}{ Comprehensive HIV/AIDS knowledge level } \\
\hline & Yes & No & Number & COR(95\%CI) & $\operatorname{AOR}(95 \% C I)$ \\
\hline \multicolumn{6}{|l|}{ Sex } \\
\hline Male & 68 & 371 & 439 & 1 & 1 \\
\hline Female & 32 & 238 & 270 & $0.73(0.47,1.15)$ & $0.86(0.54,1.39)$ \\
\hline \multicolumn{6}{|l|}{ Literacy level } \\
\hline No formal education & 10 & 69 & 79 & 1 & 1 \\
\hline Primary & 76 & 253 & 329 & $2.07(1.02,4.22)^{*}$ & $2.1(0.99,4.56)$ \\
\hline 12 and above & 17 & 35 & 52 & $3.35(1.39,8.09)^{*}$ & $3.47(1.34,8.97)^{*}$ \\
\hline \multicolumn{6}{|l|}{ Living arrangement } \\
\hline With parents & 103 & 379 & 482 & 1 & 1 \\
\hline Friends/partners & 61 & 129 & 190 & $1.74(1.20,2.53)^{*}$ & $1.58(1.05,2.40)^{*}$ \\
\hline Relatives and others & 13 & 24 & 37 & $1.99(0.98,4.05)$ & $2.35(1.07,5.17)^{*}$ \\
\hline \multicolumn{6}{|c|}{ Sources of HIV information } \\
\hline Parents & 10 & 45 & 55 & 1 & 1 \\
\hline Health workers & 10 & 79 & 89 & $0.57(0.22,1.47)$ & $0.46(0.17,1.24)$ \\
\hline \multicolumn{6}{|c|}{ Knowledge of other STIs } \\
\hline Yes & 162 & 424 & 586 & $2.75(1.56,4.86)^{*}$ & $1.95(1.06,3.59)^{*}$ \\
\hline No & 15 & 108 & 123 & 1 & 1 \\
\hline \multicolumn{6}{|c|}{ Ever discussed about sexual matter with parents } \\
\hline Yes & 54 & 91 & 145 & $2.13(1.44,3.15)^{*}$ & $2.36(1.53,3.64)^{*}$ \\
\hline No & 123 & 441 & 564 & 1 & 1 \\
\hline \multicolumn{6}{|c|}{ Having current sexual partner } \\
\hline Yes & 139 & 380 & 519 & $1.46(0.98,2.19)$ & $0.99(0.62,1.56)$ \\
\hline No & 38 & 152 & 190 & 1 & 1 \\
\hline
\end{tabular}

N.B: *=Statistically significant association at $\mathrm{p}$-value of $<0.05$.

\section{Discussion}

The finding of this study reveals that, only a quarter of out of school youths had comprehensive HIV/AIDS knowledge. The knowledge was more common among out of school youths with secondary and above educational level, who live with their friends/partners or relatives/other persons like neighbor, who use media as their major HIV/AIDS information source, who had knowledge of sexually transmitted infections other than HIV/AIDS and those who discussed about sexual matter with their parents or other family members.

The level of comprehensive HIV/AIDS knowledge in this study was comparable with the findings of the study conducted in eastern Hararge zone (24.5\%) (10). But it was lower than recent Ethiopian demographic and health survey (34\% for males and $24 \%$ for females) (5), study conducted in Butajira district (14) and higher than study conducted in Kenya in which only 3\% of those aged 15-19 and 6\% of those aged 20-24 have comprehensive knowledge of HIV/AIDS (12). The difference might be as a result of difference in the time gap between this study and the former studies.

In this study there was an association between literacy level and comprehensive HIV/AIDS knowledge. Respondents with secondary and 12 and above educational level were about two and half and almost three times more 
likely to have comprehensive HIV/AIDS knowledge respectively compared to respondents with no formal education. This finding is supported by recent EDHS (5), study conducted in north west Ethiopia, in which, respondents with elementary education were three and half times more likely to have comprehensive HIV knowledge compared to those who were not able to read and write (13) and study conducted in Ghana in which literates were seven times more likely to have HIV/AIDS knowledge compared to respondents with no formal education (14). The reason may be literate respondents can improve their knowledge on HIV/AIDS by reading different books, posters and magazines than those with no formal education. In addition to the above reason, literate respondents are more interested to listen to media and interpret it than respondents with no formal education.

Living arrangement was also associated with comprehensive HIV/AIDS knowledge, in that; respondents who live with their friends/partners and those who live with their relatives/other persons were two and two and half times more likely to have comprehensive HIV/AIDS knowledge respectively compared to respondents who live with their parents. This finding is supported by study conducted in Ghana in which respondents who lived alone or with their friends had significantly higher knowledge of HIV/AIDS as compared to those who live with their parents (14). This may be since youths prefer to communicate freely about sexual matter with their friends/partners and other persons than their parents, especially in parents where discussion about sexual matter is considered as a taboo. Furthermore, some traditional parents put restrictive order on their youths to stay away from peers and not to listen to sexual related discussion, further limiting their access to HIV/AIDS knowledge.

Respondents who cited media as their major HIV/AIDS information source were more likely to have comprehensive HIV/AIDS knowledge compared to those who cited their parents. This finding is supported by study conducted in eastern Hararge (10). The reason may be since mass media address sexual and reproductive health topics including HIV/AIDS more openly in a matter that attracts youths' attention than parents. In addition, parents may not have adequate knowledge about HIV/AIDS to provide adequate information for their youths.

There was a significant association between having knowledge of sexually transmitted infections other than HIV/AIDS and comprehensive HIV/AIDS knowledge. In that, respondents who had knowledge of sexually transmitted infections other than HIV/AIDS were almost two times more likely to have comprehensive HIV/AIDS knowledge compared to their counterparts. This finding is supported by study conducted in Gonder, where respondents who know one or more sexually transmitted infections other than HIV/AIDS were more likely to have HIV/AIDS transmission and prevention knowledge (6). The reason may be due to common causative factors of the two diseases and knowledge of one leads to know the other.

Discussion about sexual matter with parents or other family members was associated with comprehensive HIV/AIDS knowledge. Respondents who discussed about sexual matter with their parents or other family members were almost three times more likely to have comprehensive HIV/AIDS knowledge compared to respondents who were not discussed the issue with their parents or other family members. This finding is in-consistent with study conducted in eastern Hararge zone (10) in which there is no significant association between discussion about sexual matter with parents and comprehensive HIV/AIDS knowledge. But it is consistent with study conducted in Nekemte town (15) and study conducted in Cameroon (16). This may be since respondents who discussed about sexual matter with their parents or other family members also discuss about HIV/AIDS and other sexually transmitted infections compared to respondents who consider discussion about sexual matter with their parents as a taboo. In addition, respondents whose parents allow them to discuss about sexual matter with them also freely discuss about the issue with other persons to improve their knowledge on sexual issues including HIV/AIDS.

\section{Strength and Limitation of the Study}

\subsection{Strength of the Study}

This study tried to find out comprehensive HIV/AIDS knowledge level in rural communities.

\subsection{Limitation of the Study}

$\checkmark$ Being cross sectional makes this study difficult to establish temporal relation ship

$\checkmark$ Social desirability bias may be introduced

\section{Conclusions and Recommendations}

About $25 \%$ of respondents had comprehensive HIV/AIDS knowledge. Factors associated with comprehensive HIV/AIDS knowledge were literacy level, living arrangement, having knowledge of sexually transmitted infections, sources of HIV/AIDS information and discussion about sexual matter with parents or other family members. Based on the study findings, the following recommendations are forwarded.

District administration and district health office should collaborate with each other to intensify HIV/AIDS related IEC that focuses on those who live with their parents, who have no formal education and importance of parent-youth communication in communities of the district throughout reach program. District health office should be responsible to establish youth friendly health services at each health institution in the district to attract youths and educate them about sexual and reproductive health including prevention of HIV/AIDS. Parents and other family members should be encouraged to discuss about sexual matters including HIV/AIDS related issues with their youths through HEW. Federal ministry of education should be responsible to 
incorporate sexual and reproductive health to the teaching curriculum at lower classes. In addition, since there is scarcity of studies that assesses comprehensive HIV/AIDS knowledge levels of out-of-school and rural youths in Ethiopia, further studies will be needed.

\section{Authors' Contribution}

GK wrote the proposal, participated in data collection, analyzed the data and drafted the paper. LO and YD approved the proposal with great revisions and revised subsequent drafts of the paper. DM contributed in the designing of the methodology and write-up. All authors read and approved the final manuscript.

\section{Acknowledgement}

Authors would like to thank Haramaya University, College of medical and health sciences, school of post graduate studies for initiating them to conduct this study. Deep appreciations have gone to Wayu Tuka district administration office, Wayu Tuka district health office and all administrators of the six kebeles of the district which were included in the study. Special thanks to all residents of the selected kebeles, data collectors, supervisors and all peoples who involved in the study directly or indirectly.

\section{References}

[1] WHO. Early marriages, adolescent and young pregnancies Report by the Secretariat Sixty-Fifth World Health Assembly A65/13 Provisional agenda item 2012.

[2] Omobuwa O., Asekun-Olarinmoye E. O. And Olajide F. O. Knowledge and perception of reproductive health services among in-school adolescents in Ile-Ife, Osun State, Nigeria. Journal of Medicine and Medical Sciences 2012, 3(7):481-488 Available online http://www.interesjournals.org/JMMS

[3] Cherie A, Berhane Y. Knowledge of Sexually Transmitted Infections and Barriers to Seeking Health Services among High School Adolescents in Addis Ababa, Ethiopia. J AIDS Clinic Res 2012, 3:153.

[4] UNESCO. Strategy for HIV/AIDS prevention and control 2011.

[5] CSA- [Ethiopia] and ICF International. Ethiopia Demographic and Health Survey 2011. Addis Ababa, Ethiopia and Calverton, Maryland, USA: Central Statistical Agency and ICF International 2012.

[6] Shiferaw Y., Alemu A., Girma A., Getahun A., Kassa A., Gashaw A., Alemu A., Teklu T. And Gelaw B. Assessment of knowledge, attitude and risk behaviors towards HIV/AIDS and other sexual transmitted infection among preparatory students of Gondar town, North West Ethiopia. BMC Research Notes 2011, 4:505

[7] Awala E. Adolescent Sexual and Reproductive Health Service Utilization in Tigray, Ethiopia Relief Society of Tigray 2005.

[8] Alemayehu S., Mesganaw F., Alemayehu W. Reproductive health needs of out-of-school adolescents: A cross-sectional comparative study of rural and urban areas in northwest Ethiopia, Ethiop.J. Health Dev 2006, 20(1)

[9] Population Census Commission. Summary and Statistical Report of the 2007 Population and Housing Census. Addis Ababa: Federal Democratic Republic of Ethiopia, 2008.

[10] Oljira L., Berhane Y., and Worku A. Assessment of comprehensive HIV/AIDS knowledge level among in-school adolescents in eastern Ethiopia. Journal of the International AIDS Society 2013, 16:17349

[11] Mitike M., Yemane B., and Bernt L. Perception of Ethiopian youth regarding their risk of HIV: A community-based study among youth in predominately rural Butajira. Ethiopian Journal of Reproductive Health 2009, 3:3

[12] El-Zanaty and Way. Egypt Demographic and Health Survey 2008. Cairo: Egypt Ministry of Health and Population and Egypt population council 2009.

[13] Berihun M. And Taddesse A. Comprehensive knowledge, attitude and practice of street adults towards human immunodeficiency virus/acquired immune deficiency syndrome (HIV/AIDS) in Northwest Ethiopia. Journal of AIDS and HIV Research 2013, 5(6):181-187, http://www.academicjournals.org/JAHR

[14] Agyemang S., Buor D. And Tagoe-Darko E. The extent of knowledge about HIV/AIDS among young people in the Ejura-Sekyedumase district of Ghana. Journal of AIDS and HIV Research 2012, 4(11): 241-247.

[15] Tesso W., Fantahun A. And Fikire E. Parent-young people communication about sexual and reproductive health in E/Wollega zone, West Ethiopia: Implications for interventions. Reproductive Health 2012, 9:13

[16] Tsala D., Kuate D. Fostering accurate HIV/AIDS knowledge among unmarried youths in Cameroon: do family environment and peers matter? BMC Public Health 2011, 11:348. 